\title{
Correction to: Water pollution characteristics and analysis of Chaohu Lake basin by using different assessment methods
}

\section{Xiong Yang ${ }^{1} \cdot$ Hongbiao Cui ${ }^{1,2} \cdot$ Xiaosheng Liu ${ }^{1} \cdot$ Qiugang $\mathrm{Wu}^{1} \cdot$ Hui Zhang ${ }^{3}$}

Published online: 21 April 2020

(C) Springer-Verlag GmbH Germany, part of Springer Nature 2020

\section{Correction to: Environmental Science and Pollution Research} https://doi.org/10.1007/s11356-020-08189-2

The correct presentation of the Figure 1 image is shown in this paper.

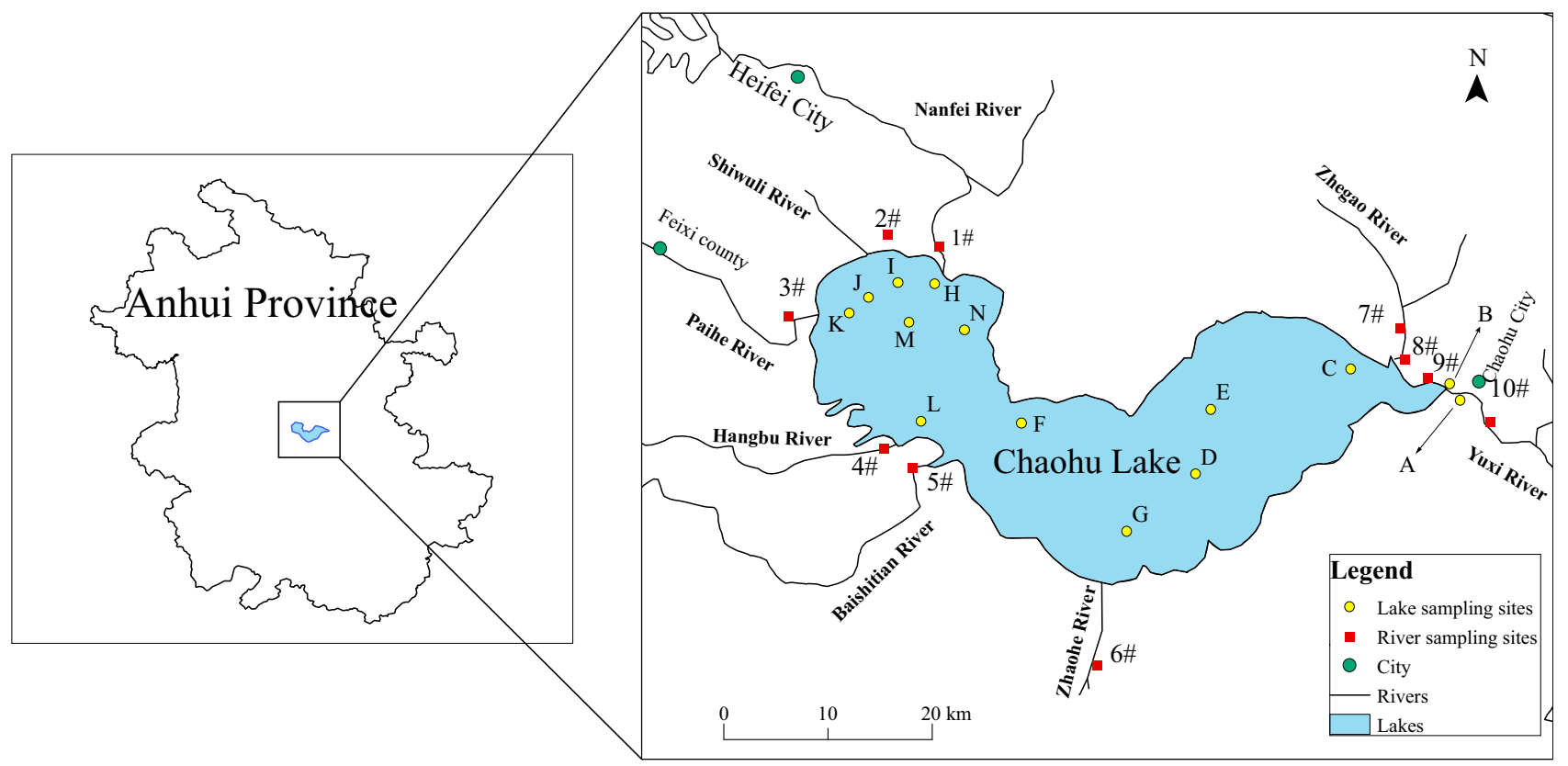

Fig. 1 Sampling locations in Chaohu Lake basin

Publisher's note Springer Nature remains neutral with regard to jurisdictional claims in published maps and institutional affiliations.

The online version of the original article can be found at https://doi.org/10. 1007/s11356-020-08189-2

Xiong Yang

yangxiong2016@foxmail.com

$\triangle$ Hongbiao Cui

cuihongbiao0554@163.com

School of Earth and Environment, Anhui University of Science and Technology, Huainan 232001, China
2 Key Laboratory of Soil Environment and Pollution Remediation, Institute of Soil Science, Chinese Academy Sciences, Nanjing 210008, China

3 Environmental Protection Monitoring Station of Chaohu Authority, Chaohu 238000, China 